\title{
FACTORS AFFECTING AGING WORKFORCE MANAGEMENT IN KHO WANG, YASOTHON PROVINCE, THAILAND
}

\author{
Wijittra Srisorn \\ Sunthan Chayanon \\ Suan Sunandha Rajabhat University, Bangkok, Thailand \\ Tikhamporn Punluekdej \\ Southeast Asia University, Bangkok, Thailand
}

This research on the factors affecting management of the aging workforce in Kho Wang, Yasothon Province aims to: 1) study the factors affecting management of the aging workforce; and 2) provide guidelines on management of the aging workforce at Kho Wang District, Yasothon Province. This is a qualitative research in which data are derived from literature review in various forms such as text books, research papers, academic materials as well as specialized journals and magazines. Content analysis has been selected as a research methodology, and data presentation is descriptive in nature. The results show that transformation leadership style and management of diversity are important factors that provide positive effects on management of the aging workforce in Amphoe Kho Wang, Yasothon Province. The changing structure of population towards aging society produces a severe shortage at the labor market. As a result, there are less young people joining the
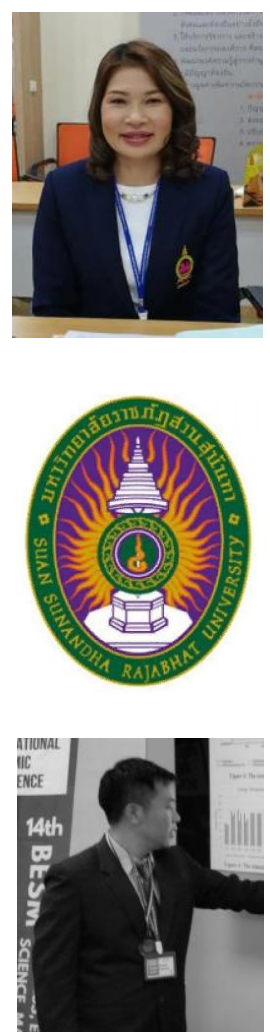

\section{Wijittra Srisorn}

$\mathrm{PhD}$, Asst. professor in College of Innovations and Management, Suan Sunandha Rajabhat University, Bangkok, Thailand

Science interests: national policy, legislative system, Governance, economy and social regulation

E-mail: wijittra.sr@ssru.ac.th

\section{Sunthan Chayanon}

$\mathrm{PhD}$, lecturer in College of Innovations and Management, Suan Sunandha Rajabhat University, Bangkok, Thailand

Science interests: national policy, legislative system, Governance, economy and social regulation

E-mail: sunthan.ch@ssru.ac.th

\section{Tikhamporn Punluekdej}

$\mathrm{PhD}$, Lecturer in Graduate School, South-East Asia University, Bangkok, Thailand Science interests: national policy, legislative system, Governance, economy and social regulation

E-mail: tikhamporn.pu@gmail.com 


\section{FACTORS AFFECTING AGING WORKFORCE MANAGEMENT}

workplace. Thus, every organization has to deal with the situation when it lacks employees. Therefore, appropriate management of elderly workforce becomes a challenging issue in HR management for the near future. Firms should be able to use the skills, knowledge, capacity, expertise as well as accumulated experience from the older workers in order to benefit their own organizations.

Keywords: management; aging workforce; human resources; Kho Wang District; Yasothon Province; Thailand

\section{Introduction}

Population structure always has its effects on the labour market. Changes in labour patterns thus always become a challenge for human resource management (HRM). As a consequence, organizations must be ready to cope with the changing structure of the workforce situation. Firms should look for appropriate guidelines for management of human resources, especially management of the aging workers, in order to create stability for the organization (Ruta \& Rasa, 2014). At present, workforce management in terms of age discrepancy is considered as an important and challenging issue in relation to the decreasing number of younger workers and the increasing number of older workers (Pinto et al., 2015).

Today, older workers in Thailand represent $39.4 \%$ out of the total workforce in the country. At the moment, Thai government has provided both direct and indirect support to older workers, for instance, providing loans for occupation-related matters and issuing other related policies that are in favor of the working elderly. Regardless of whatever efforts the government makes to support older workers, one of the most important things on the side of employers and general entrepreneurs is that they should render opportunities for the elderly to demonstrate their full and genuine potential. At the same time, the government may take action to boost the motivation among business entities to recruit older workers into their regular workforce, for example, through tax allocation. On the other hand, aging workers should be empowered in order to realize that they have sufficient potential and capability and are needed by the society to participate in the development of labour market and national economy (Aumsuk, 2015).

The changing structure of Thai population already shows that it is expected to become an aged society in 2017 already. This trend has its obvious effects on the economy, society, and labor problems. The government should prepare necessary measures related to development of human capital in order to deal with the current situation and solve the labor shortage problems since older workers are already the majority of the total workforce. The said is reinforcing measures that can take the forms of tax advantage, skills' and expertise promotion programs, social networking for the elderly based on community governance, and various alternative labor shortage solutions, all being aimed at reducing the severity of the aging society phenomenon.

Such attempts may include the increment of the fertility rate in order to increase the number of working people. A new public policy should be implemented to encourage families to have more children (Worapatthirakul, 2017). The demographic data of Yasothon province reveal that there are 539,284 people in the province these days. The said figure can be divided into the following categories: childhood (0-14 years old) at the number of 106,317 people $(19.71 \%)$, compulsory education age (5-19 years old) at the number of 
116,664 people (21.63\%), working age (15-60 years old) at the number of 373,396 people (69.24\%), working age with income (20-60 years old) at the number of 332,225 people $(61.60 \%)$, and old age (60 years old and above) at the number of 59,571 people (11.05\%). Porramet Saeng-on, Pichet Kerdvichai, and Surachet Suchaiya (2018) put forward the idea that often the informal laborers are not really taken into account in such statistics, such as entrepreneurs or self-employed individuals, for instance, singers, taxi drivers, merchants, farmers, and various types of freelancers.

Social dimension and quality of life in the province have been analyzed via SWOTanalysis. Among the strengths the following items have been mentioned: an adequate number of education establishments, local people are equipped with multidisciplinary knowledge and indigenous wisdom, there is an adequate number of public healthcare facilities, local society is peaceful, there is a large number of factories in the region, infrastructure is acceptable, and there is also an adequate amount of drinking water. Weaknesses, in their turn, include: lack of life-long learning system, low education quality, less number of medical staff and public healthcare officers, poor public hygiene, potential risks of epidemic situation, lower quality of life as only minimum basic needs are covered. 712 households in this region have the income lower than 23,000 baht per capita; many people are in huge debts, thus labor migration becomes widely spread, especially among unskilled and undisciplined labor. There are also serious problems with female and child labor, with handicapped people, and vulnerable older people (http://www.yasothon.go.th/web/manage/manage7.html).

Promotional as well as supporting programs from various sides such as governmental units, private sector, local administration offices, community units and other related units are necessary to bring back this aging population into the labor force since they urgently need to earn a living, for both themselves and their families.

Most of these older people have low economic status and desperately need income for survival or, at least, for reducing the burden of their families. These aging people do not work for pleasure or hobby. These elderly may work individually, in various occupational groups, for community enterprises and/or cooperatives. At the moment, there is quite a number of these types of work scattered around the country. It would be wise to collect data and understand the lessons learned by the types of work performed by these older working people in order to discover the processes, important factors, and necessary mechanisms that support the opportunities for the older working people.

Attempts should be made to determine the best practices for older working people. Such useful information will lead to a synthesis that may result in measures, guidelines or a better choice of policy pertaining to employment of older people.

From the above discussion, the researchers are deeply interested to study the factors that have their effect on the employment of older people in Kho Wang district, Yasothon province. New guidelines on labor management of aging people at Kho Wang district, Yasothon province will definitely be useful for both practical application and future empirical studies in this direction.

\section{Objectives:}

1. To study the factors that affect the management of aging workforce in Kho Wang district, Yasothon province, Thailand.

2. To suggest the guidelines on management of the aging workforce in Kho Wang district, Yasothon province. 


\section{FACTORS AFFECTING AGING WORKFORCE MANAGEMENT}

\section{Literature review}

According to contemporary human resource management (HRM), HR managers must be responsible for managerial functions that integrate both internal and external factors in achieving harmony of work operations. Today's management also focuses on the prevention of problems that may arise in the foreseeable future rather than tries to solve the problems when they already happened. Human resource management begins with recruiting the best qualified personnel who are knowledgeable, capable, and highly enthusiastic to join the organization.

Then goes training and developing their potential in relevance to the changing situation and business strategy. HR managers need to come up with the ways and means to reveal the full potential of the available human resources and to keep the most efficient workers with the organization (Cheuabangkraw, 2012).

Management overall must treat human resource management as an important tool which is increasing the productivity of older workers by creating motivation for employees and adjusting the organization to cope with the constantly changing situation (Kasia Karpinska, 2015).

In contemporary business operations, managers have a crucial annual mission -- to develop the organizational strategy. For example, when faced with economic challenges, firms will react with a challenging tactics to increase their employees' operational effectiveness. These efforts may be an increment to company's competitiveness, or related cost reduction, or improvement of employees' performance, or letting the supervisors participate in formulation of organization's strategy relevant to their assigned work responsibilities (Cheerakarn, 2014).

Any organization with appropriate recruitment and selection system will be able to attract personnel of good quality to work in it. These people, once they are already working in the organization, will be capable to utilize all of the firm's production factors to produce the output as specified by the company. As a consequence, such personnel is really worth the investment, as it can create customer satisfaction, and it produces much profit and thus, eventually lead the organization to success. Human capital can also create value added for the company by using its intellectual capital. The wit of human beings can create endless value for the company when compared with other production factors which are always disposable (Cheuabangkraw, 2012).

Thai government has declared that the retirement age for all governmental officers is at 60 y.o. as specified in the Government Pension Act, 1951. There is no retirement age for the private sector though. However, the law has set a specific age for certain rights and social security benefits being 55 y.o. (Jamjan, 2013).

The increasing number of old-age population has produced some effects on the labour market (Chen, Kamibeppu, \& Murayama, 2010). Thailand is now gradually becoming an aging society. On top of that, there is both demand and supply in the employment of old-age people. This becomes logical, as there is an obvious need to promote and support the employment of older people. If one considers the knowledge, abilities and experience of the older people, their employment is one of the appropriate solutions that benefits Thai society as a whole.

When the elderly has work to do, they can earn decent income, and they can enjoy a suitable quality of life. In their turn, businesses can use the expertise possessed by senior 
people to maintain their competitive advantage. Their tacit knowledge can be transferred to the next generation. Thus, the government would be able to allocate money to support other projects instead of using it to support the growing number of old people (Sadanghan, 2015).

As mentioned earlier, Thailand has specified the retirement age only for government units. There is no retirement age for the private sector as such. Therefore, management of elderly workers becomes much more challenging since the number of working people is decreasing and the population structure is changing in terms of diversity and age of the workers. Humans are different from each other in many ways, and age difference is only one of them. Age does have a significant relationship with capability to perform work operations (Pinto, da Silva Ramos \& Nunes, 2014).

In the future, the shares of working age people, teenagers, youngsters and children would, most probably, decrease continuously. When the older people are retired and there won't be sufficient volume of replaceable workforce, plus the industrial sectors are already unable to find human resources to fulfill all the vacancies. This becomes a disaster from the macroeconomic perspective of the whole country, and is especially threatening for the economic growth of the agricultural sector, industrial sector and services sector. When the social dimension of this problem is considered, the retiring people often have no adequate savings, they have no income to live life, and no financial security. Thus, their financial burden falls on the government which is expected to look after the old age people, their quality of life, public services provided to them and any other necessary welfare aspects.

When we look at this problem at the individual and family levels, the impacts may be seen in various forms, such as healthcare problems, illnesses, hospitalization expenses, the responsibility to take care of the older members of the family and so on. Also, there are various economic difficulties. All of these issues get interrelated and eventually become one same issue (Suwanrada, 2016). The increasing number of older people makes their group much more important (Chen et al., 2010). The aging labour force is important to economic development at both regional and community levels (Fellow, 1956).

Organizations should be ready to cope with the changing structure of population and the increasing number of aging workers. Firms must find appropriate ways to make use of the older workers in order to strengthen the organization's stability (Ciutiene \& Railaite, 2014). The older workforce can be compared with human capital of the company in which they are equipped with skills and capability that can increase the productivity of the firm (Youndt, Subramaniam, \& Snell, 2004). The working status is one of the important factors in life. It is apparently clear that older working people have more chances to enjoy better psychological health than those who do not work. Therefore, if there is space for expansion of the working period for the elderly, this will definitely improve their quality of life and psychological health of the old. This has been already confirmed by the study carried out by Rashid Shar Baloch (2014). This author has found that aging employees as active participants in business operations have many dimensions and significant influences on processes and productivity of the organization due to their experience, knowledge, and forecasting skills.

Organizations are highly likely to be affected by the timely or untimely retirement of such employees, therefore, organizations' owners (top managers) have their interest and concerns over this issue. Older employees are priceless assets and at the same time, to some extent, potential problem for the organization. Assessment of pre-retirement sentiments at micro, meso and macro levels can gauge the degree of loyalty and engagement of employees, and the latter two are very important for optimum productivity and overall performance. 


\section{FACTORS AFFECTING AGING WORKFORCE MANAGEMENT}

Similarly, the perceptions that are being developed in the minds of aging employees are important factors to be analyzed.

Hence, this study has found that aging employees developed and sustained some expectations, opportunities, confusion and fallacy in their mind right before their retirement. The research has also found that keeping older workers in a company can increase the overall productivity of the firm. Capability of older workers is a crucial factor on which the company should focus. In this respect, the company should pay appropriate attention to management of older workers and their needs. This will lead to the development of aging workforce.

Matin and Sabagh (2015) conducted a research on the effects of knowledge management capabilities on organizational performance in Iranian export companies with the purpose to investigate the relationship between knowledge management capabilities and organizational performance. The knowledge management indices included knowledge process capabilities (knowledge acquisition, knowledge transfer, knowledge protection and knowledge application) and knowledge infrastructure capabilities (organizational culture, organizational structure and technology), while organizational performance indices were organizational innovation and competitiveness and financial/economic outcomes. The key method of their study was structural equation modeling. The results of confirmatory factor analysis determined that both research models demonstrate significant estimations. Also, the result of path analysis determined that there is a direct and significant relationship between organizational culture, organizational structure, knowledge acquisition, knowledge application, knowledge protection and organizational performance. This study is the first one, to this day, to investigate the relationship between knowledge management and performance in Iran. It would be valuable for Iranian export companies to apply the results of this study in their knowledge management, taking into account the determined effects on organizational performance.

\section{Methodology}

This is a qualitative research in which data are obtained from various sources, including textbooks, academic articles, research papers, and other related materials. The data analysis has been done through content analysis, and data presentation is descriptive in nature.

\section{Results}

Factors affecting the management of aging workforce at Kho Wang district, Yasothon province

The transformation leadership style

At present, rapid changes and overall instability of business environment have their impact on the way business entities are organized. This phenomenon inevitably sends a signal to the HRM strategy. HR managers must be ready to face the changing business environment (Thongpan, 2016).

Excellent change management means being able to transform attitudes, values, skills, knowledge and capabilities of employees. HR managers are expected to have an important role and to participate as change agents, organizational designers, work planners, process 
organizers, and facilitators who are using their HR functions to support organizational change.

Bass and Avolio (1994) conducted a study on transformational leadership and found that there are 4 important characteristics of such a style: 1) idealized influence, to formulate vision and mission of the organization, being a leadership model, 2) motivational inspiration, to communicate with followers, to convince employees about the importance of organization, to motivate workers to perform according to the shared vision, 3) intellectual motivation, to encourage creativity among followers leading to a new concept, 4) individualized consideration, to provide a comfortable atmosphere that encourages supporting, listening and counseling in the hope that followers will develop themselves towards the organizational goals.

The presently changing situation has its effects on the HR managers who are encountering new challenging tasks in which traditional HR functions are not working anymore. As a result, HR managers must adapt their paradigm. The concept of HR function should be relevant to the context and the organization, however, both are changing all the time. This functional adaptation would increase the competitive abilities and guarantee sustainable survival of a company. In this regard, employment of the aging workforce, when practiced, will help the firm benefit from their knowledge, capabilities and long-lasting experience of the older workers in the course of building competitive advantage (Sadangharn, 2015). Therefore, older workers should be considered as the group of potentially most intelligent workers inside a company. This is in line with the study conducted by Garavan, Carbery and Rock (2012) on talent development. Their research has found that the support from the leader who realizes the changing structure will enable organization maintain this intelligent group of older workers within the company. The organization must draw up a clear career-path goal for the elderly workers. This becomes one of the crucial factors in talent management that will bring success to the company.

Basing on the above literature, it can be concluded that transformation leadership has a positive relationship with management of the aging workforce.

\section{Diversity Management}

Diversity management means management of factors that bring in differences among the people in a company, for instance, age, sex, race, religion, language, personality, knowledge, way of thinking, working model, experience, working role, socioeconomic status, and various need of workers (Daft, 2012). Management of diversity is both a challenging job and an opportunity in the development of organization by HR managers.

Diversity of personnel reflects the differences of people. In this respect, HR managers must understand the factors pertaining to human differences since these differences will affect human resource management and the use of diversity to benefit the firm. Diversity can increase working capacity, create wider perspectives and provide various skills needed to solve different kinds of problems a company might be facing.

The organization must find ways and means so that different workers can use their differences to co-perform the work without the feeling of alienation due to their age, sex, race, cultural background etc. According to (Daft, 2012), all employees must be treated equally and should be experiencing the same kind of work satisfaction.

Diversity management in relation to older workers in an organization is very important. The failure to include diversity management might lead to a situation when a firm will lose 


\section{FACTORS AFFECTING AGING WORKFORCE MANAGEMENT}

valuable workforce with high intelligence and rich experience. Thus, diversity management in the context of age is becoming a challenging job for managers who are dealing with the increasing age diversity in firms. Management of aging workforce usually covers such issues as inflexibility, resistance to change, lack of capability, and lowering ability to learn new things.

Most of successful organizations are known to be practicing diversity management. Organizations must realize and appreciate diversity in its various dimensions. Diversity may and should be treated as a valuable asset of company.

People should respect diversity, learn about diversity, convert their own diversity to be used inside the company in order to build creativity and motivation leading to sustainable success (Thumviriyavong, 2016).

Gokcen (2012) conducted a research on diversity management and found that firms must pay attention to differences among employees. These differences have both pros and cons. Organization must be able to draw these differences and apply them to suit the work operations for the better of the firm. This is also in relevant to the research conducted by Ozgener (2008) titled "Diversity Management and Demographic Differences-Based Discrimination: The Case of Turkish Manufacturing Industry". This author has found that workforce today becomes more diverse in terms of demographic changes, cultural differences and other characteristics of organizational members. This diversity is an immediate reflection of changes happening at global markets.

Workforce diversity has both positive and negative effects on organizational performance. Therefore, it is becoming important especially for medium- and large-scale businesses. In order to manage this increasing workforce diversity and to prevent discrimination due to various diversity issues, diversity management is now considered to be a major part of strategic human resource management. The findings of various research studies indicate that demographic characteristics, sociocultural structure, managerial policy and behaviors, union tendencies and regional differences, laws and local community development, gender, educational and age differences as well as political opinions, all have influence on discrimination. Thus, discrimination has been observed mostly in job processes such as promotions and appointments, human resource selection, job/employment examination and interviews, and then later during performance appraisal.

From all of the above, it can be inferred that diversity management has a positive impact on management of the aging workforce.

\section{Province}

Guidelines on Management for Aging Workforce, Kho Wang District, Yasothon

Knowledge Sharing Organization

In the knowledge-based economy, knowledge is a driving force of any economy striving for prosperity and employment, both including the ability to compete. Knowledge becomes the major resource of any organization, and its importance is explained by its radical difference from other factors of production, especially in the era of boundless communication. The organization's chance for success will depend on the company's ability to manage personnel's knowledge. Organizations can use employees' tacit knowledge in

order to survive. The use of knowledge will become successful only once sharing is included in the development of knowledge through the mechanism of knowledge transfer. This is 
considered to be the most important process in knowledge management. Knowledge sharing is an activity that connects individuals and organization through transformation of tacit knowledge of employees into the organizational level. This process focuses on the optimum of work operations. As a consequence, knowledge sharing can actually reduce timeconsuming practice of trial-and-error among coworkers in the workplace. In some professions, the thinking process of older workers can benefit the most for success of overall operations. This is because of the expertise and experience of the elderly leading to overall higher productivity.

As Thailand is approaching the stage of aging society and there is a need in both supply and demand for hiring older people, it becomes logical to consider the employment of aging workers. If we consider the knowledge, capability and life-time accumulated experience of the older workers, it is very easy to conceive that employment of aging workers is one of the most appropriate alternatives for Thai society. Now the elderly have work to do, they can earn income, and they can have a better quality of life according to the needs of their age. Also, in such a way, organizations can pass on individual knowledge to the next generation of workers inside their own structure (Sadangharn, 2015). Thus, it can be concluded that management of the aging workforce is a positive factor in relation to knowledge sharing.

\section{Organization's Knowledge Sharing and Organizational Performance}

Organizational performance is generally assessed using financial indicators such as return on investment or profit per share. This narrowness of criteria for measuring organizational effectiveness is in fact a phenomenon of range restriction having consequences on the way managers organize work and manage people in organizations. It is often argued that the greater is the range among the performance criteria, the greater would be the value of work experience. Drawing from the empirical study, four dimensions of organizational performance are described along with their potential impacts on the meaning of work. Several avenues for managing organizational performance constructively are proposed, for example, in (Morin \& Audebrand, 2014). Many business entities have a tendency to adjust the traditional way of doing work and build their own, new model of operations relying on knowledge as the most valuable asset of their company.

The organizational learning process creates value and competitive advantage for the firm (Tiwana, 2001). The knowledge-sharing process is considered as a social interaction in which experience, thoughts, and skills are exchanged through various units and organizations. Knowledge sharing is a truly important factor for the body of knowledge. It is believed that it is a type of management aimed to change individual knowledge into organizational knowledge, thus, improving organizational performance.

As a result, knowledge sharing as a business process produce an impact on organizational performance. Chen and Fong (2012) in their research study titled "Revealing performance heterogeneity through knowledge management maturity evaluation: A capability-based approach" found that dynamic capabilities view (DCV) focuses on the renewal of firms' strategic knowledge resources so as to sustain competitive advantage within turbulent markets.

Within the context of DCV, the focus of knowledge management (KM) is to develop the knowledge management capability (KMC) through deploying knowledge governance mechanisms that are conductive to facilitating knowledge processes so as to produce superior business performance over time. The essence of KM performance evaluation is to assess how 


\section{FACTORS AFFECTING AGING WORKFORCE MANAGEMENT}

well $\mathrm{KMC}$ is configured with knowledge governance mechanisms and processes that enable a firm to achieve superior performance through matching its knowledge base with market needs. Alaaraj, Bustamam, and Mohamed (2016) in the course of their research "Mediating Roles of Trust on the Effects of Knowledge Management Capabilities on Organizational Performance" revealed that the effects from the process capabilities component of the knowledge management capability are more dominant for organizational performance than its infrastructure capabilities. In addition, the effects on organizational performance are in sharing, utilization, and acquisition of knowledge (in that particular order) followed by organizational culture and structure, and finally technology infrastructure. Finally, the mediating role of trust was confirmed.

Thus, building organizational trust between employees and managers could enhance organizational performance. Wang, Sharma, and Cao (2016) did a research under the title "From knowledge sharing to firm performance: A predictive model comparison". These authors indicated that knowledge sharing contributes to firm performance through the enhancement of innovation and/or intellectual capital, they confirmed this using the data collected from Chinese high-tech firms. Their results showed that in the best performing model, innovation and intellectual capital simultaneously mediate the relationship between knowledge sharing and firm performance in this specific context.

All these findings offer insights on the parallel mediation roles of innovation and intellectual capital in knowledge sharing. This can help managers set priorities while leveraging knowledge sharing to achieve specific performance goals. Therefore, firm's knowledge sharing is proved to be a factor highly relevant to business performance.

\section{Conclusions and Discussion}

Management of aging workforce is a challenging issue in human resource management of the firm level, especially in the context of upcoming labour shortages. Organization can utilize skills, knowledge, capabilities, expertise and accumulated experience of older workers for their own benefit. This knowledge sharing will eventually lead to higher effectiveness of firm's performance.

Thus, organizations should pay more attention to management of aging employees so that to get extra competitive advantages and reach sustainable development. Factors affecting management of aging workforce include transformational leadership in which organizations set the top priority on leaders and/or managers who must adjust their paradigm to be relevant to the changing human resource management depending on a present situation, and diversity management where individual differences in age can be used to benefit the firm and are applied to suit with the type of work performed. These efforts are believed to produce excellent performance of firms.

Nuttita Devalersakul, Wanida Siriwarakoon and Chartsarun Roadyim (2016) conducted a research under the title "The Development of the Elderly as a Burden to Power: Case Study of Rangsit City Municipality" and discovered that:

1) problems and obstacles of the elderly include: 1.1) no personnel to take care of the elderly, 1.2) the available budget does not cover the needs of the elderly, 1.3) there are limitations in authority of Rangsit City Municipality when it comes to welfare management of the elderly, 1.4) physical weakness and illnesses of the elderly, 1.5) 
mental and emotional frustration from physical health problems and environmental related problems, 1.6) economic problems, and 1.7) insufficient income;

2) the potential of the elderly includes: 2.1) most of the elderly enjoy systematic thinking, experience, knowledge, leadership potential, and nearly perfect communication skills, 2.2) there is a less number of the elderly who use their knowledge and expertise to develop the community, and 2.3) the elderly are more than happy to participate in the activities organized by the community itself and in the development of their own community;

3 ) the needs of the elderly include: 3.1) a healthcare center for regular check-ups, 3.2) various kinds of trainings and retrainings, 3.3) higher income for survival, and 3.4) love and care from their relatives;

4) approaches to turn a burden into a power: 4.1) there should be more recreational activities for the elderly, 4.2) there should be seminars on occupational opportunities for the elderly carried out by respectable speakers, and 4.3) there should be a club for the elderly with a president and a liaison.

Development of guidelines on management of aging workforce in Kho Wang district, Yasothon province should first of all start with the realization of a changing population structure in the country. This change has already obvious impacts on Thai labour market. On the top of that, less and less young workforce is entering the local workplaces. Organizations must find brand new ways to deal with the current labour shortage situation. Therefore, management of aging workforce becomes a challenging issue for human resource management in part of dealing with labour shortages in the near future already. Organizations can use skills, knowledge, capabilities, expertise, and accumulated experience of the older workers to benefit their own development. This is in parallel to the work by Suppanunta Romprasert (2014) on "Aging Population and the Readiness of Thai Government".

This author used mixed methods of research, combining a survey research with a descriptive one. This study has been expected to find out and explain the aging phenomenon and the readiness of Thai government to treat all of the related issues. The findings showed that factors affecting readiness and preparation of the older workers for the labour market include educational, occupational and income dimensions that the elderly have accumulated during their working life. The government, in its turn, should prepare totally new ways to handle the problems of aging people before the latter actually reach their retirement period. Thus, communication between the state and the older people is important in order to raise awareness among those who work and to prepare them for their own retirement.

Promotion of positive attitudes between the older people and their family members is believed to help building a decent attitude and feelings in terms of self-awareness in personal values in the older people. The research also pointed out that Thai government has already provided some welfare management for the elderly through cooperation among the public, private and the people's sectors.

The work by Kulisara Pinthong, Sucheap Piriyasmith, and Decha Buatayt (2018) under the title "The Quality of Life Development of the Elderly, Sing Buri Province" had the main objective to study the quality of life development of the older people along with the problems, obstacles, and guidelines on the development of life quality for the older people in Sing Buri province.

The results of this research indicated that Sing Buri province has entered the stage of the aging society in the year 2014. Some of the local older people are taken care by their own families or other relatives. They have no stable income, as they used to work in the 


\section{FACTORS AFFECTING AGING WORKFORCE MANAGEMENT}

agricultural sector for many years, now they have to look after their younger relatives, they are often with debts, lack savings, and without any financial planning as such. Problems and obstacles of the elderly in Sing Buri province include: lack of support from their families, self-worthless feelings, and chronic sicknesses and various illnesses related to the old age.

From the economic perspective, it is found that the elderly have no permanent occupation and as a result, they have no stable income, they have quite an amount of debts incurred by their family members, they experience no extra income except life-sustaining allowance from the state.

The research also suggested that the Department of Older People, Ministry of Social Development and Human Security, should support a work plan and a specific budget for the official units at the provincial level that are involved in organizing promotion campaigns of the elderly association at every possible level. These campaigns may include encouragement for the elderly to enter the elderly school based on the Ba-vorn principle (Home, Temple and School).

Last but not least, there should be an elderly clinic in the sub-district hospital for health support of the elderly specifically. Governmental units should also promote generation of additional income for the older people by working hand-in-hand with other related units in an integrated manner.

\section{Suggestions}

Management of the aging workforce is still only a planned concept for human resources management in organizations that are already struggling to cope with labor shortages and would like, at the same time, to make use of knowledge, capabilities and experience of the older workers. As a consequence, such organization should pay much more attention to management of the aging workers in order to get extra competitive advantage and reach sustainable development of the company overall. From our review of literature sources, one of the most important factors affecting successful management of the aging workforce is transformational leadership which, in a nutshell, means that organizations must focus on their leaders and/or managers who, in their turn, must adjust their paradigm to suit the changing HR management realia by assessing the present environmental factors and considering the importance of diversity management. In this context, age differences can be smartly used to benefit the whole organization, if applied properly it to suit the types of works performed. This will eventually lead to much better operations for the whole company. If firms are being able to manage all related managerial factors in the company, including all the issues related to continued employment of the older workers, it is rather obvious that the company, in a longer term, will become more successful. Such knowledge management processes can be shared among other business entities in order to bring success and high effectiveness to other firms as well.

\section{References:}

Amrit, T. (2001). The Essential Guide to Knowledge Management: E-Business and CRM Applications. New Jersey, NJ: Prentice Hall.

Aumsuk, R. \& Sukhonthamarn, P. (2015). Aging Workforce: Situation and Policy in Thailand. Journal of Politics and Governance. Population Studies. College of Population Studies. Bangkok: Chulalongkorn University: 345-364. 
Baloch, Rashid Shar. (2014). Aging Employees' Retirement Perceptions, Intention and Behaviours. Paper presented in the Pakistan Society of Sugar Technologists Conference, Lahore.

Bass, B.M. \& Avolio, B.J. (1994). Improving Organizational Effectiveness through Transformational Leadership. Thousand Oaks, CA: Sage Publications.

Cheerakarn, K. (2014). Human Resources Management in Modern Business (From Now to the Future). Suthiparithat Journal, 28 (86): 322-337.

Chen, Junxia, Kamibeppu, Kiyoko, \& Murayama, Shiho (2010). Factors Related to Well-being Among the Elderly in Urban China Focusing on Multiple Roles, BioScience, 4 (2): 61-71.

Chen, Le \& Fong, Patrick S. (2012). Revealing performance heterogeneity through knowledge Management maturity evaluation: A capability-based approach. Expert Systems with Application. 39 (18). 13523-13539.

Cheuabangkraw, P. (2012). Human Resource Management. Pathomthani: Bangkok University Press.

Ciutiene, R. \& Railaite, R. (2015). Challenges of managing an aging workforce. Engineering Economics, 26 (4). 69-73.

Daft, R. L. (2012). Management. Mason, Ohio: South-Western Cengage Learning.

Devalersakul, N., Siriwarakoon, W. \& Roadyim, C. (2016). The Development of the Elderly as a Burden to Power: Case Study of Rangsit City Municipality. Veridian E-Journal, Silpakorn University. 9 (1): 529-545.

Fellow, E.W. (1956). A Study of the Factors Related to a Feeling of Happiness. Journal of Education Research, 50: 231-234.

Garavan, T. N., Carbery, R. \& Rock, A. (2012). Mapping talent development: definition, scope and architecture. European Journal of Training and Development, 36 (1): 5-24.

Gokcen, A. (2012). Diversity in Diversity Management. International Journal of Business and Social Science, 3 (19): 241-244.

Jamjan, C. (2013). A Consideration for a New Concept of Elderly People and Retirement Age In Thailand. Thai Population Journal, 4 (1). 131-150.

Karpinska, K. (2015). Training Opportunity for Older Workers in the Netherlands: A Vignette Study. Research in Social Stratification and Mobility, 41: 103-112.

Matin, E. K. \& Sabagh, P. (2015). Effects of Knowledge Management Capabilities on Organizational Performance in Iranian Export Companies. Mediterranean Journal of Social Science, 6 (2): 239-250.

Morin, E. M. \& Audebrand, L. K. (2014). Organizational Performance and Meaning of Work: Correcting for Restricted Range. Available online at: https://www.researchgate.net/publication/277313498_Organizational_effectiveness_and_the_m eaning_of_work .

Pinthong, K., Piriyasmith, S. \& Buatayt, D. (2018). The Quality of Life Development of the Elderly, Sing Buri Province. Pathumthani University Academic Journal, 10 (2): 110-120.

Pinto, A., da Silva Ramos, S.C.M, \& Nunes, S. (2014). Managing an Aging Workforce: What is the Value of Human Resource Management Practices for Different Age Groups of Worker? Review of Applied Management Studies, 12: 58-68.

Romprasert, S. (2557). Aging Population and the Readiness of Thai Government. Economics and Public Policy Journal, 5 (10): 16-25.

Saad, A., Ummi, B., Ahmad, S. \& Zainal Abidin, M. (2016). Mediating Roles of Trust in the Effects of Knowledge Management Capabilities on Organizational Performance. Social and Behavioral Science, 235: 729-738.

Sadangharn, P. (2015). The Employment of Older People in Thailand. Human Resources Institute, Thammasat University, Bangkok.

Saeng-on, P., Kerdvichai, P. \& Suchaiya, S. (2018). Development of Working Life Quality for Taxi 


\section{FACTORS AFFECTING AGING WORKFORCE MANAGEMENT}

Drivers. Journal of Rajanagarindra, 15 (33): 195-204.

Sevki, O. (2008). Diversity Management and Demographic Differences-Based Discrimination: The Case of Turkish Manufacturing Industry. Journal of Business Ethics, 82 (3): 621-631.

Suwanrada, W. (2016). Old People Moving Toward Aging Society with Knowledge and Wisdom. Bangkok: The Thailand Research Fund.

Thongpan, S. (2016). Proactive HR in the Changing Era. Graduate Studies Journal, 10 (3): 245-258.

Thumviriyavong, P. (2016). Workforce Diversity Management. Academic Journal of Bangkokthonburi University, 5 (2): 1-12.

Wang, Z., Sharma, P. \& Cao, J. (2016). From knowledge sharing to firm performance: A predictive model comparison. Journal of Business Research. 69 (10): 4560-4658.

Worapatthirakul, P. (2017). Labor Problems: When Thailand Enters the Aged Society. Bangkok: Western University.

Paper submitted

Paper accepted for publishing

Paper published online
16 May 2019

19 July 2019

08 August 2019 